\title{
LA ANTROPOLOGÍA DE LA DEMOCRACIA: EL DEMÓCRATA EN LA ORACIÓN FÚNEBRE DE PERICLES
}

\author{
Antonio Hermosa Andújar
}

es professor de Historia de la Ideas Políticas en la Universidad de Sevilla. Sevilla, AN, España.

E-mail:hermosa@us.es

Orcid: 0000-0003-1588-5764

http://dx.doi.org/10.1590/0102-031054/107

Atenas se sirve del tributo a los muertos (tras el primer año de la guerra contra los lacedemonios) como excusa para tributar homenaje a los vivos, aprovecha lances habituales en una guerra como coartada para elogiar la democracia, esto es, su propio régimen político; lo hace por boca de Pericles, su reiteradamente electo estratego y orador insigne. ${ }^{1}$ ¿Se trata de una, en el fondo impía, desconsideración hacia aquéllos, con todos los atenuantes circunstanciales que se quiera -guerra, dolor, esperanza, etc.-, o más bien de un acto de justicia técnicamente casi baladí? De ser lo primero habría supuesto quizá la mayor revolución en el ámbito de las creencias en el mundo antiguo, tan radical como para parecer inconsciente. ¿Pero cómo podría ser lo segundo? ¿Por qué un vivo aprovecharía la ocasión de un muerto para trazar un panegírico de sí mismo? ¿Por qué una

\footnotetext{
1 Tucídides le dedicará un sobrio pero convincente elogio al hablar de su muerte, y en él destacará al menos dos cosas: el sumo papel que había llegado a desempeñar en Atenas (que "de nombre" era una democracia, pero "de hecho" no era sino "el gobierno del primer ciudadano") y su condición de "insobornable", como enfatiza Laura Sancho Rocher (2017, p. 252) para distinguirlo de la otra gran figura elogiada, Temístocles. Plutarco ya había destacado de él que pese a haber asumido poderes absolutos (dando así razón a Tucídides, II, 65-9) no había aumentado la hacienda heredada de su padre en un solo dracma (Vida de Pericles, II, 15-3). Añadamos que la singularidad de su liderazgo ya fue resaltada en su día por Aristóteles (Constitución de los atenienses, 28, 1), idea que aprovecharía M. I. Finley (traducción nuestra), para remachar que "la muerte de Pericles constituyó un punto de inflexión en la historia social del liderazgo ateniense". Cf. Finley (1962, pp. 3-24) y luego, ya revisado, en su propio libro Democracy Ancient and Modern; nosotros hemos citado por la edición de P. J. Rhodes (2004, p. 177).
} 
comunidad fingiría necesitar la muerte para darse prueba de orgullo y de valor?

Ahora bien, el orador no olvida el sufrimiento para mercadear con la memoria colectiva. La "luz de sus palabras", por parafrasear libremente a Federico García Lorca, no hurga en semejante tiniebla sencillamente porque no quiere centrarse especialmente en los muertos, y ni siquiera en la muerte, aunque también lo haga, sino en la vida, y en este punto es precisamente la democracia-patria la encrucijada de todos los destinos, el hogar que acoge los pasos y justifica las hazañas de todos, de los muertos como de los vivos, el inmortal cañamazo cuya historia entrelaza las vidas de los ciudadanos en un perpetuo continuum donde no caben el antes y el después del tiempo o de la muerte. Los muertos son, pues, no sólo pero sí sobre todo el salvoconducto por el que una democracia idealizada coloniza mediante el recuerdo los mundos apolíticos, como la acción de todos lo es de la colonización de los mundos políticos. Aquéllos merecen veneración y recuerdo en tanto que testimonios vivientes de lo que han sido, y los vivos que los recuerdan no son sino la herencia de lo que habrían podido y querido seguir siendo. Justo por eso el orador que desde lo alto de la tarima se dirige a los presentes les habla también a ellos al hablar a los demás, y de ahí que no empiece por sus nombres y demás sellos personales, sino por el hogar común que sus antepasados forjaron en el tiempo y ahora forja a todos, sabedores se diría de que al principio los hombres forman las instituciones antes de que las instituciones formen a los hombres, como un día dirá Montesquieu.

La democracia es por tanto el primer gran personaje que sale a escena en el homenaje a los caídos durante el primer año de guerra, la arcilla que modeló a los ausentes y a los que aún están, como también, se espera, a los que vendrán (Tucídides, 2000). Luego de breves disquisiciones sobre la conveniencia o no de tales discursos, sobre la envidia que persigue a los hombres allá donde vayan, sin 
excepciones de tiempo y lugar (envidia que se cela en el protagórico hombre medida de todas las cosas y cuyo poder es tal que se permite flanquear el entero discurso), ${ }^{2}$ su papel de primera dama reivindicará un lugar estelar en la obra incluso allí donde, al final de la misma, las palabras del orador dan palmadas en la espalda a los caídos y de consuelo a sus familiares, ${ }^{3}$ desde el momento en que el ambiente privado en el que resuenan no deja de ser un altavoz público de la heroicidad de sus acciones. ${ }^{4}$ Por qué éstas se producen naturalmente en determinados contextos, y la naturaleza de los individuos que las llevan a cabo con dicha naturalidad; o, en suma, cómo son los demócratas y qué les guía en su acción, será en esta ocasión el modo que tendremos de encarar la democracia ateniense, una tarea que desde otras perspectivas más amplias ya desarrollamos en otros lugares. ${ }^{5}$

Nos proponemos en las páginas que siguen desentrañar las cualidades y los ideales más sobresalientes que distinguen al demócrata ateniense, así como constatar cómo el género humano se ha perfeccionado volviéndose más complejo con aquéllos. Pasemos por tanto a exponer la antropología de la democracia.

\section{El legado de los antepasados}

El demócrata actual tiene pasado: ¿qué le llegó de él? La certeza de que desde el inicio ${ }^{6}$ sus ancestros habitaron esa

\footnotetext{
2 Aparece, en efecto, casi al principio y al final del mismo, en los pars. 35 (2) y 45 (1) esto es, el segundo y el antepenúltimo respectivamente, para erigirse en el único motivo por el cual dudar de la grandeza de los homenajeados.

3 Mediante el consuelo, y no con compasivos lamentos, señala expresamente Pericles (Tucídes, 2000).

4 De ahí que Pericles enfatizara que "lo principal del elogio" a los caídos "ya está dicho" aun antes de empezar a hablar expresamente de ellos (Tucídides, 2000).

5 Cf. Hermosa Andújar (2000, 2008).

${ }^{6}$ Aunque eso sea lo que nos diga Pericles se sabe que la historia, como la naturaleza kantiana, quiere otra cosa, y en lugar de la autoctonía y la pureza racial pondrá conquista y mezcla de pueblos y culturas.
} 
tierra y por siempre la mantuvieron libre, es decir, ajena a toda dominación exterior. Y la anexa de que tan titánica gesta

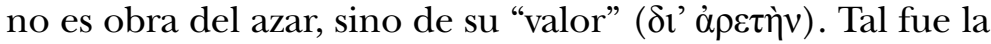
lección aprendida de las generaciones más antiguas, pero la inmediatamente precedente, la que derrotó a los persas, añadió otra: la formación del imperio, más la convicción de que tampoco fue regalo del azar, sino de su esfuerzo: una transformación de las circunstancias políticas conseguida "no sin

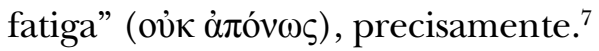

El ciudadano de hoy, que ha sumado potencia a su imperio y dispuesto la ciudad para la guerra y la paz haciéndola "autosuficiente", se injerta así en un tronco antiguo cuyo fruto lejos de contravenir las raíces resulta su natural desarrollo. La autarquía moderna revigoriza la autoctonía antigua, y con ella la libertad que la siguió, que además de externa pasó a ser también interna. La libertad, en efecto, no se predica naturalmente de la autoctonía, pues unos habitantes por así decir nacidos de la tierra no tienen por qué permanecer libres: su tierra, como cualquier otra, no se oculta a las poderosas ambiciones foráneas y éstas, se sabe, logran satisfacer asiduamente sus objetivos. De hecho, lo que ha creado y preservado la corona de la libertad sobre el trono de la autoctonía no fue tal hecho, sino el valor de sus habitantes, una adquisición extraída por ellos de las circunstancias y legada como un tesoro indeleble a sus herederos, pues como el orador recordará al final de su discurso con palabras áureas "la felicidad se basa en la libertad y la libertad en el

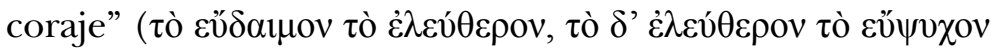

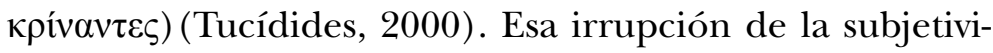
dad en el mundo objetivo de los hechos se refuerza con otra propiedad más antes de desembocar en el reconocimiento antevisto de que el destino propio está en mano de cada

\footnotetext{
7 En la realidad, y especialmente en el presente, la línea no fue tan recta, sino más bien conflictiva, como pone de relieve A. Tsakmakis citando a B. Strauss; cf. Tsakmakis (2017, pp. 170-171).
} 
uno, si bien se requieren tales condiciones: la del esfuerzo como medio de satisfacción de nuestros deseos, como método de lograr nuestros objetivos. La libertad, externa e interna, cedería ante el acoso enemigo sin valor y la grandeza con la que defenderla permanecería como un sueño veleidoso y peligroso si se creyera que pende de la ruleta de la fortuna -capricho divino incluido-y no del esfuerzo personal más o menos entretejido en un proyecto común. ${ }^{8}$

\section{El demócrata y la democracia}

El valor y el esfuerzo, incrustados en el sujeto autónomo al que dan forma, constituyen las condiciones de la libertad y son la materia con la que el yunque de la historia ha forjado al demócrata, y por tanto también a la democracia, ya que "las excelencias" que adornan a Atenas derivan justamente de sus ciudadanos. ${ }^{9}$ Empero, al darse tal forma de organización política para ordenar la convivencia interindividual, el demócrata aprende enseñanzas nuevas que enriquecen su patrimonio personal, tanto en lo referente a su psicología, su ética y su política como al propio bienestar material.

\section{El demócrata y la vida pública}

Pericles se ufana de la singularidad de la constitución ateniense, una rara avis incluso en el interior de la civilización helena, a la que llama democrática por ser la "mayoría" quien decide en ella. La igualdad en la participación política o isegoría subraya la radical igualdad legal de los libres,

\footnotetext{
${ }^{8}$ Aunque el breve flash histórico pericleo parezca trazar la línea recta del progreso como vínculo de unión entre las generaciones, sin embargo, la concepción del tiempo en Tucídides no es lineal, sino circular (al respecto véase el recentísimo artículo de Carlo Marcaccini en el estudio monográfico citado más arriba, pp. 213-234).

9 Pericles afirma dicha idea en relación a los caídos, y justo a continuación de la frase antes citada por nosotros del par. 42, 2. Dice así: "dado que las excelencias por las que he ensalzado nuestra ciudad son el ornamento que han procurado las

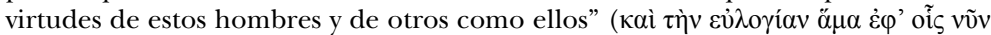

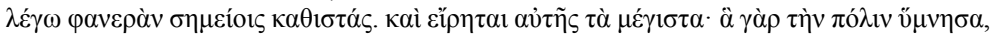

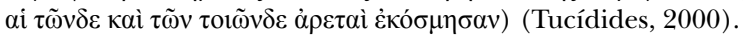


con independencia de toda circunstancia sociológica, histórica, profesional, etc. Sólo se reconoce en dicho ámbito una forma de desigualdad que, en realidad, es la que completa el círculo de la igualdad jurídica: la selectiva del mérito, que hace de la política ateniense una política meritocrática. En la selección de quienes desempeñarán los cargos públicos él será, en efecto, el árbitro.

Es la aristocracia por tanto la que de esa manera se introduce en la constitución, pero no la aristocracia sociológica, sino la técnica de la capacidad personal. Lo cual entraña toda una revolución antropológica que corona otra social: no es la clase de pertenencia la que ahora decide sobre el mérito, que así, de un solo golpe, por un lado deja de pertenecer a las clases en bloque, y por otro corta el cordón umbilical que antaño lo transmitía por herencia, ese arte de magia con el que la naturaleza es transmutada en sociedad. De ahí que ahora ya todos los aristócratas no sean necesariamente meritorios, o en consecuencia no cuenten para el mérito la tradición o el linaje, el nombre y el pasado o cualquier otra gloria ajena al talento personal. Y de ahí también, y ésta es la gran revolución, que al pobre se le abra la vía del heroísmo y de su fama por cuanto la inteligencia se ha abstraído de la herencia, de la situación social o profesional, y que a todos, en principio, quepa optar a los cargos unipersonales que confieren auctoritas a quien los ejerce dignamente y prestigio a la ciudad así regida. Abolir el vínculo natural entre pobreza y capacidad, o, en otras palabras, extirpar el vicio de lo que sólo es una situación sociológica, no sólo supone suprimir el estigma moral que la persigue como si se tratara de una maldición, sino cortar de un tajo el nudo gordiano que ahogaba la extensión de la igualdad por los confines de la libertad.

No termina ahí la revolución. Que el mérito sobrevuele el entero arco de la sociedad y no repare en clases, historia, profesiones, etc., a la hora de elegir a sus individuos 
es, cierto, prueba irrefutable de que la naturaleza no nos quiere a todos iguales, y que el igualitarismo es sólo una manifestación de violencia con la que el mediocre ascendido al poder se rebela contra ella; pero es también algo más: y, en concreto, la afirmación de que son muchos los filósofos que pueden desempeñar los cargos políticos de mayor responsabilidad, vale decir: la negación de que la política sea una techné más según la querencia de Platón, y por lo tanto privilegio exclusivo no ya de una casta, sino de un solo individuo por sociedad. El mérito, que discrimina naturalmente entre los hombres por abajo, lo hace también por arriba, lo que permite a los de abajo recuperar su lugar natural en la política al mismo tiempo que desmantela la tiranía de un robespierre menor reciclado por la idea regia de bien. Así pues, el mérito termina de modelar la revolución democrática de igualdad para la libertad al acompasar la política a la naturaleza humana, esto es, al racionalizar las funciones políticas, al jerarquizarlas y distribuirlas en base a las capacidades de quienes las desempeñen. Lejos de anular la igualdad al introducir diferencias en su seno, da con el lugar apropiado para ellas en el organigrama de la política.

El demócrata aprendió con su democracia nuevas enseñanzas. La básica: que no hay ciudad sin obediencia política, y en una en la que él gobierna y elige a otros que le gobiernan, obedecer las leyes que gobiernan a todos y también a sus magistrados supremos constituye una condición sine qua non contra la anarquía y a favor de la vida misma. La reverencia a dichas autoridades tiene sus preferencias en el corazón del demócrata, que extiende a las leyes que defienden a quienes padecen injusticias y a determinadas tradiciones, que no se pueden infringir sin pagar el duro precio de la vergüenza pública. Así pues, la obediencia es el correlato de la libertad, pero también, en una democracia directa, el correlato del poder. No habría libertad donde la anarquía dicta su regla, porque es su simple contrasentido, y la 
anarquía constituye el brillante producto final de una desobediencia organizada hacia la ley y el gobernante. Pero eso carece de más sentido todavía cuando uno de esos gobernantes, o mejor, varios de ellos, son precisamente quienes obedecen, dado que lo hacen a sí mismos: si no obedecieran las leyes no podrían, por ejemplo, elegir a sus gobernantes, ni juzgarlos después, con lo que habrían depreciado el valor su función y el poder sus competencias. En una democracia directa obedecer es, en determinados casos, simplemente actuar, es decir, ejecutar el poder.

\section{El demócrata y la vida privada}

El demócrata que aprendió igualdad para su libertad -hoy diríamos derechos políticos- al participar en el ejercicio del poder político es consciente de que la igualdad no puede acabarse $a$ a $^{10}$ y trocar poder por esclavitud en la vida privada; sabe más bien que la libertad ha de manifestarse aquí en forma de igualdad de derechos civiles y que ello implica mucho más que la igualdad ante la ley. Aparte de reconocer que ser pobre no le hace despreciable, sino que sus méritos, caso de tenerlos, le ayudan a trascender en el ámbito público su condición económica, regresa a casa después del ejercicio de sus funciones con nuevas ideas en sus alforjas. Su acción pública le ha enseñado el valor de la cooperación y la responsabilidad de la acción, y si bien su vida social quede quizá lejos de aquélla, y su vida personal le distancie aún más, sabe que la responsabilidad ante los demás, aunque no sea tan directa como en su trabajo público, no desaparece en el ámbito particular. Y la principal de todas es la gestión de su propia vida privada.

El ciudadano se sabe con obligaciones públicas, pero el individuo se sabe con derechos privados; lejos de la

10 "La libertad de que gozamos en nuestro gobierno se extiende también a nuestra vida cotidiana" (Tucídides, 2000). 
asamblea, del consejo o de los tribunales su vida es algo que se rige por sus deseos y sus decisiones, de las que a nadie tiene que dar cuenta y que tienen como límites supremos las normas, escritas o no, que rigen a la comunidad. Pero es lo radicalmente autónoma como para no dar cuentas personales a los demás de cuanto libremente decide hacer y llevar hacia adelante sus proyectos como realmente le venga en gana. Un derecho ese que en la vida privada conlleva su propio límite en el respeto del derecho de los demás a hacer lo mismo, y por tanto a no sancionar a los diferentes con esos reproches y esas miradas de censura que él no espera recibir de ellos, de modo que la tolerancia y el valor de cierta diferencia brotan de un solo golpe y de la misma fuente: la autonomía personal con la que la igualdad sanciona la libertad. ${ }^{11}$ Como nos dirá más tarde Tocqueville, la igualdad concurre con la libertad en personalizar la vida del sujeto particular en su ámbito privado, y ese triunfo individual de la sociedad, que Pericles reconoce como propio de Atenas y de los atenienses, constituye el gran tributo rendido por la cultura helena al individualismo, presente en infinidad de aspectos de la misma pero que aquí llega a su cénit: no hay vida libre sin la tolerancia que exige la diferencia que nos distancia de los demás. La tolerancia, una función de la libertad en realidad, marca el límite que reconoce o niega la soberanía del individuo sobre sí mismo y sobre los demás en el espacio único de su vida personal.

Igualdad legal, pobreza emancipada por la participación y trascendida por el mérito, es decir, con acceso al ámbito público, y libre disposición de su vida que genera el derecho a la diferencia y el deber de la tolerancia constituyen por tanto el resumen de la retirada del ciudadano de la democracia ateniense a su ámbito privado o personal.

11 Acerca de la importancia del concepto de autonomía en Tucídides, que nosotros, lógicamente, apenas si tratamos aquí, puede verse el excelente artículo de Maria Gerolemou (2017). 


\section{La nueva antropología}

¿Influye convivir en un régimen democrático sobre el decálogo moral de sus ciudadanos y/o sobre la propia naturaleza humana?

La pregunta parece un ejercicio de soberbia en sí misma, en especial en lo concerniente al segundo punto, en tanto el primero quizá parece más al alcance de sus posibilidades. Centremos una vez más nuestra atención en las palabras del orador y veamos qué sacamos en claro.

\section{Democracia y valores}

Pericles no hurta al enemigo el enorme valor con el que sus soldados acuden a la guerra en defensa de la propia ciudad, pero enseguida añade que sus ciudadanos no le van a la zaga en eso. Un idéntico coraje bulle en el corazón de ambos bandos cuando se aprestan a dirimir su suerte en el campo de batalla, pese a la diferencia, se diría ontológica, 40 que les separa en sus respectivas visiones de la vida, su educación y su organización política y militar. La democracia, entonces, ¿nada tiene que aducir en su favor?

En realidad, lo que a nuestro entender las palabras anteriores sugieren es más bien lo contrario. En el momento sin retorno en el que la vida puede desaparecer ante la muerte y el azar no ha decidido aún qué opción tomar, el valor con el que cada sociedad afronta a la otra en defensa de sí misma puede llegar a ser idéntico, pero hasta llegar ahí, vale decir, en el conjunto de la vida, en todo cuanto hay detrás del momento decisivo de jugársela, las vías son distintas. Eso significa, sí, que es posible alcanzar idéntica meta por medios diversos y aun opuestos, pero por lo mismo que la coincidencia en el punto de llegada en absoluto cancela las divergencias en el punto de partida. ¿Qué es lo que les diferencia, tanto a la ciudad como a sus ciudadanos?

Incluso en la guerra Atenas se ofrece como una ciudad abierta, que se publicita ante los extranjeros en lugar de 
expulsarlos, y renunciando por tantos a los supuestos beneficios del secreto, que en el ámbito militar se suponen siempre decisivos. La razón es su valor: esa valentía, ese ardor y esa audacia que mana del fondo de ellos mismos, de los ideales y principios que les animan en todas las facetas de la vida y que actúan de consuno al entrar en acción; tan en contraste por demás con el penoso adiestramiento y los engaños propios del enemigo. Lo que subyace a semejante actitud es la confianza en las instituciones en que aquéllos encarnan y, más aún, la confianza en sí mismos; y lo que subyace a dicha confianza es la autonomía de unos sujetos que han fijado mediante deliberación mutua cómo quieren ser y actuar, y que al dar forma plena a tales objetivos no necesitan de instrumentos externos -una educación austera y gravosa, un ejercicio continuo y fatigoso, unas leyes estrictas que los traigan constantemente a su memoria- para transformar su pasión por ellos en coraje y en defenderlos con vehemencia llegada la ocasión. El demócrata que estipula junto a otros como él el destino de su sociedad no necesita de un Estado que le diga cómo sentir ni cuándo actuar; él ya transformó dicho destino en una segunda piel y por tanto su naturaleza, por sí sola, se dispara como un resorte cuando una amenaza ensombrece el horizonte.

Esa vida mucho más relajada pero de la que el valor forma parte consustancial se reveló todavía mejor en la paz. Un sensual hedonismo, tan contrario al estoico de Epicuro, hacía danzar el placer en torno a los objetos de la vida cotidiana, y los ciudadanos lo derramaban pública y privadamente ${ }^{12}$ en fiestas y juegos colectivos -con los que reforzaban su identidad y su patriotismo, tanto local como heleno,

12 Como bien dice Domenico Musti (2000, p. 137), "no un hedonismo puro y simple, sino una filosofía del derecho a la felicidad en libertad, en un clima de igualdad formal para todos, donde la ley garantiza a cada cual lo que hoy llamaríamos la libre manifestación de la propia personalidad, a partir de los 'derechos del cuerpo'": tan opuesto, insiste en nota, al sôma-sêma, el cuerpo-tumba de los órficos. 
y el espíritu se unía al cuerpo en el goce-, o bien en viviendas lo bastante pertrechadas y cómodas como para vacunarles contra las fatigas y sinsabores que la vida regala a sus visitantes casi a diario. ${ }^{13} \mathrm{El}$ imperio añadía nuevos veneros de disfrute, porque aportando productos de los pueblos con los que comerciaba uncía al bienestar material dicha cotidianeidad aumentando su goce (Tucídides, 2000). ${ }^{14}$

Eran esas ganancias de la vida cotidiana un modesto lujo al que el ateniense no pensaba renunciar en ningún caso, máxime porque lo sabía compatibilizar con el valor en las ocasiones de peligro; era ese hedonismo, compaginable igualmente con la pasión por la libertad y la igualdad, el que había operado nuevas transformaciones en su espíritu que había trasladado a su vida distanciándole aún más del habitante de cualquier otra ciudad o imperio. El sufrimiento, y las agonías de que se rodea, tendrían que buscar en otras almas el fuego inmisericorde de esas creencias que devoran el sentido común y la racionalidad y humillan la vida. Él no se afligiría como un resignado ante los males que el futuro traerá ni perdería su tiempo en combatir contra los

13 Lea el lector la cancioncilla que abre La Mandragola de Maquiavelo y podrá observar la llamativa afinidad electiva aquí creada por la historia (Machiavelli, 2006, p. 463).

14 No deja de resultar llamativo que en el recuento de las formas de placer enumeradas por Pericles como propias del ateniense no entre ninguna de las actividades intelectuales que hicieron grande a Atenas en Grecia y a Grecia en el mundo, contraste tanto mayor en cuanto Homero aparece relegado a realzar el valor de culturas que necesitan ser cantadas por el aedo para merecer reconocimiento en lugar de obtenerlo mediante sus propias acciones. Pero ni la literatura, ni la filosofía y ni siquiera la historia aparecen entre las formas de placer que la época cultivaba disfrutando del ocio y de la tranquilidad. Como dice P. Christodoulou (2017, p. 153): "It is worth pointing out that from the end of the fifth century words such as jovхía, $\sigma \chi 0 \lambda \eta \dot{\eta}, \dot{\alpha} \pi \rho \alpha \gamma \mu \sigma \sigma u ́ v \eta$, were explicitly linked with the ideal of vita contemplativa and more precisely with the individual who is exclusively devoted to the act of writing a political, philosophical text”. Ausencia esa que brilla aún más cuando se recuerda cuánto debe la razón griega a la ciudad, según pusiera de relieve Pierre VidalNaquet (1990) en su La raison grecque et la cité. No es por cierto la única ausencia, ya que hay otras más inmanentes a un discurso de dicha naturaleza que tampoco aparecen, pues falta toda alusión a la piedad y al sentimiento religioso que, como bien dice Adolfo J. Domínguez Monedero (2013, p. 26), "uno esperaría encontrar también en un discurso de este tipo". 
fantasmas que cerebros desbocados crean al enfrentarse a las desgracias -o aun a las gracias, cabría añadir- que desafían la cordura de la existencia. Él preservaría la suya contra viento y marea en tanto las penalidades no le afectaran, y cuando éstas acaeciesen su osadía intentaría tornar nuevamente a su favor la situación. El pozo de miseria en el que determinadas creencias precipitan a sus víctimas no estaba hecho para él. Heredero del no te resignes, actúa, el lema con el que una Atenea travestida de Mentor, el anciano consejero de su padre, instaba a Telémaco a acudir en su búsqueda, el ateniense se sabía pertrechado con todas las cualidades psicológicas y morales con las que hacer frente a la adversidad cuando ésta apareciera ante él; mientras tanto, la participación en la vida pública, su trabajo, la atención a su vida personal y los placeres con los que intentaría disimular las fatigas que esas y otras actividades engendraban no dejaban tiempo a su razón para ocuparse de unos molinos de viento improvisadamente transformados en gigantes.

En su búsqueda de la felicidad, el demócrata ateniense, además de a las fuentes del bienestar, la acción o la racionalidad, acude a otra singularmente helena: la sofrosyne, esa moderación que, en su caso, entronca tan naturalmente con los demás valores, y ante todo con la acción, que hasta parece una propiedad más de la misma. Es ella la que está debajo de su uso de la riqueza o de la valoración de la pobreza; es la sofrosyne la que, entendemos, permite a Pericles afirmar que "nos servimos de la riqueza más como oportunidad para la acción que como pretexto para la vanagloria”, y también, justo a continuación, lo siguiente: “y entre nosotros no es motivo de vergüenza para nadie reconocer su pobreza, sino que lo es más bien no hacer nada por evitarla" (Tucídides, 2000); es decir, la que le permite, deambulando entre ambos extremos del poder social, buscar el término medio de cada uno de ellos, un punto próximo en ambos marcado por la capacidad para la acción. La riqueza, 
lejos de ser el fin de todas las cosas, como en el Creso de Herodoto, o aquello por lo que se juzgarán todas las técnicas y se emprenderán sus respectivas actividades, como nos dirá Aristóteles en su Política, deviene instrumento del que servirse en todos los aspectos de la vida al objeto de arramblar el botín de la felicidad personal; la pobreza, en su configuración antevista, liberada ya de su condición de baldón o rémora, tampoco obstruirá la acción de ningún agente en pos del mismo objetivo salvo si él mismo, mediante la resignación, la pereza, la cobardía, o cualquier otra excusa, decide devolverla a su prístino origen predemocrático.

\section{Democracia y naturaleza humana}

Los monumentos que la paz hace surgir en el interior del demócrata van mucho más allá. Y aun si la guerra permite rescatar de golpe toda una vida cuando el ciudadano que hasta entonces no se mostró digno de la democracia-patria quiera dar la suya repentina y voluntariamente por ella, la paz da pie a madurar otras vidas que no necesitan de rescate postrero para demostrar su grandeza. Vidas que, cuando se sigue detenidamente su exhibición, nos ponen ante la vista regiones desconocidas en el paisaje de la condición humana.

El ciudadano de la democracia ateniense, en efecto, no es un individuo cualquiera; ama, por ejemplo, la belleza, y ello le aleja de su rival espartano (Tucídides, 2000), ${ }^{15}$ pero con sencillez, lo que torna a distinguirle de un Creso; pero ama

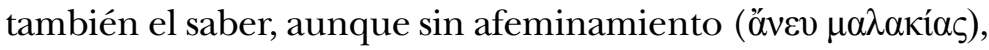
lo que le hace alejarse un paso más de los dos. Con todo, lo que ahora nos interesa destacar es que ama a ambos, belleza y saber, aunando de este modo en su persona la sensibilidad y la inteligencia, la dimensión estética -sentidos y sentimientos

\footnotetext{
${ }^{15} \mathrm{Y}$, bien mirado, de la belleza espartana de un Platón y de la pátina de moralina con la que lo recubre.
} 
reunidos en la belleza- y el conocimiento -sentidos y razón reunidos en el saber-, lo que casi le convierte en un monstruo, vale decir, en un ser demasiado humano si paragonado a la mayoría de sus contemporáneos. Amar por sí la belleza, amar por sí el saber y amarlos a los dos aunque por separado significa dar forma a un individuo más complejo que al buscar su felicidad necesita poner de acuerdo potencias constitutivas ontológicamente diferenciadas entre sí y en cuyo desarrollo pueden entrar en acuerdo tanto como en contradicción; pero significa, de añadidura, haber construido un concepto de felicidad que rebasa no sólo la simple satisfacción de deseos primarios, sino el entero dominio del placer material, al que, por lo demás, en absoluto rechaza, según vimos. El espíritu se ha hecho carne entrando en el deseo, y no sólo: al seguir su rastro se le ve diferenciarse en aspectos que además de sublimes pueden enfrentarse entre sí y que plantean el deber de unificarlos como un drama interior del sujeto, como un desafío a la conciencia a fin de evitar el desvarío de la conducta. De ahí que, como se expondrá más tarde, la escena moral reclame la presencia de nuevos habitantes.

Ese sujeto ya dividido, esto es, más complejo, al que acabamos de observar prolonga en sus actos la escisión de su naturaleza, aunque no de manera mecánica. El sujeto capacitado para sentir y pensar también lo está para actuar en éste $o$ aquél campo, es decir, en más de una actividad, o lo que es igual: su racionalidad desbordará con su pericia los límites de más de una técnica sin tener que avergonzarse forzosamente ante los resultados, como exigirá más tarde Platón. ${ }^{16}$ Afirma Pericles: "Las mismas personas pueden dedicar a la vez su atención a sus asuntos particulares y a los públicos, y gentes que se dedican a diferentes actividades tienen suficiente criterio respecto a los asuntos públicos"

\footnotetext{
${ }^{16}$ Salvo para sus gobernantes, excepción que le permite reunir al menos a un par de animales a la vez en cada uno de ellos: pero ya se sabe que los miembros de dicha casta son una inmensa minoría (La República, 375e).
} 
(Tucídides, 2000). El grito de guerra de Protágoras contra Platón, afirmando que el fuego prometeico se particulariza en cada sujeto, pero la justicia de Zeus los alcanza a todos al tratarse de una virtud pendiente sólo de aprendizaje para su adquisición, se encarna aquí en un sujeto real, el ciudadano de la democracia ateniense. Es la confirmación de que la democracia es un régimen político que se ordena mediante una institucionalidad por entero singular y que requiere conformar su ciudadanía de individuos especiales para preservar su existencia, y por ende un artificio social mediante el cual el hombre abandona la naturaleza, que impone al más fuerte sobre los demás, sin necesidad de salirse de ella, en tanto nunca dejan sus instintos y sus pasiones atrás.

Ningún hombre queda ahora natural o legalmente relegado por su condición, por su profesión o por cualquier otro motivo de su derecho a participar en la vida pública, e incluso de alcanzar las más altas magistraturas si sus capacidades le avalan, como tampoco, dentro de los órganos colectivos, de debatir el orden del día, de aportar su opinión que, además, querrá informada para hacerla pesar más. La decisión llegará tras la deliberación pública de individuos convencidos de que la palabra es el argumento que transfiere la racionalidad personal a la colectiva y que el debate entre ellos configura el modo de acceder a la misma, y de que expresándola e imponiéndola una vez emitida se ha prefigurado el camino que disuelve las tinieblas que median entre el surgimiento de un problema y su posible solución. ${ }^{17}$

Leyendo con atención el texto nos parece escuchar el tono de sus palabras, detectar el orgullo que siente

\footnotetext{
17 "Nosotros en persona cuando menos damos nuestro juicio sobre los asuntos, o los estudiamos puntualmente, porque, en nuestra opinión, no son las palabras lo que supone un perjuicio para la acción, sino el no informarse por medio de la

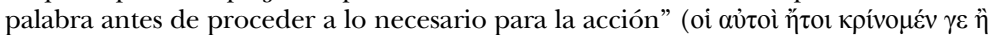

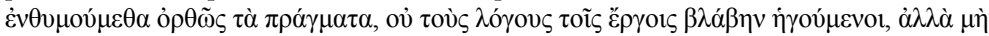

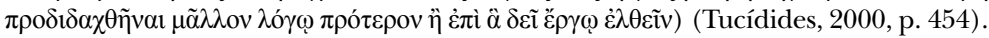


al pronunciarlas, compartir la emoción que intuimos le embarga ante las ideas expresadas, como si tuviera plena consciencia del significado de la revolución democrática en la historia, del enorme cúmulo de inercias, tradiciones, prejuicios, dogmas, violencias, etc., caído con ella (aunque no, por supuesto, del que ella misma generará), de la irrupción que le acompaña de un nuevo sujeto histórico, el hombre común, en la historia universal, ${ }^{18}$ del que ella es simplemente su naturaleza hecha política.

La grandeza de ese nuevo héroe vulgar vuelve a ponerse de relieve con quizá aún mayor intensidad al enumerar otras cualidades que acompañan a la recién citada: alaba la capacidad de sus conciudadanos a la hora de razonar sobre las acciones que van a emprender y de calcular sus consecuencias, pero reconoce al mismo tiempo la audacia con la que las llevarán a cabo, mientras en los demás, explica, la osadía promana de la ignorancia en tanto el cálculo se consume en la indecisión (Tucídides, 2000). ${ }^{19}$ Cualidades que en otros se presentan por separado en ellos lo hacen unidas, lo cual, de nuevo en un mismo golpe, nos sitúa ante un hombre mucho más complejo que sus coetáneos, el más complejo, a decir verdad, que la historia haya conseguido moldear con la naturaleza humana, a la que de continuo extrae potencialidades antaño desconocidas, y ante una reconfiguración de cualidades y valores, que en su nueva abstracción se desligan de los vínculos que antes mecánicamente les unían y les faculta por tanto para ensanchar ampliamente el círculo de las relaciones que mantienen entre sí.

\footnotetext{
18 Remedamos aquí libremente a Christian Meier (1993, pp. 7-42), en concreto su capítulo inicial en Athen. Ein Neubeginn der Weltgeschichte, en el que explica la irrupción de un cantón en la política mundial, esto es, las consecuencias políticas de Salamina. Cf. también Meier (1983, pp. 91-143), para observar el desarrollo del sujeto político de ese cantón en el interior del mismo merced a las reformas de Clístenes.

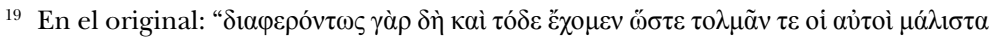

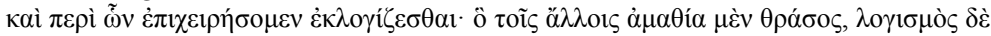

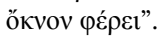


Romper mediante la acción que aúna cálculo y coraje con la ley de hierro que encadena ambas cualidades con la indecisión y la ignorancia respectivamente supone en efecto elevar un grado por encima al género humano en la escala de su auto-perfección, y de hecho poner en evidencia que el ateniense es más que dos de los otros seres desde el momento en que además de reunir en sí mismo a dos hombres opuestos multiplica la cualidad de la acción, al engranar en ella una espiritualidad por completo ajena al mecanismo casi instintivo de sus precedentes, cuyos actos se revelan ahora como puras manifestaciones de fuerza en lugar de acciones de poder, con la paradoja añadida de que en uno de esos casos, el del cálculo derrotado por su propia indecisión, ni siquiera poseía la capacidad de oponer resistencia.

En el mundo humano antiguo, por tanto, la moralidad sólo podía resolverse en el interés o, lo que es igual, en la ceguera ante las nuevas figuras espirituales que empiezan ahora a invadir ese terreno, como el altruismo o la generosidad, a las que vemos saltar de la boca del orador a la palestra de la sociedad en palabras como éstas: "También en lo relativo a la generosidad somos distintos de la mayoría, pues nos ganamos los amigos no recibiendo favores, sino haciéndolos" (Tucídides, 2000). Generosidad, y altruismo cabría añadir, devienen poder a través del desinterés del espíritu que los activa porque, primero, anudan al hombre objeto de la acción al sujeto de la misma transformando el beneficio recibido en gratitud, y segundo, pero más importante, porque el beneficiador, al no contraer mediante su acción ninguna obligación con el beneficiario, permanece libre para mantener sin mácula ese espíritu que se manifiesta en hechos que no requieren recompensa material alguna, sino que sólo precisan del favor de la propia voluntad. Y es esa continuidad en la disposición de la voluntad, como también sus consecuencias, los beneficios prolongados en el tiempo, la mayor garantía de que la amistad ofrecida por quien así 
actúa es sincera ${ }^{20} \mathrm{o}$, si se prefiere, de que el poder que dicha amistad genera -el de humillar entre otros- no se transforme en opresión en quien lo ejerce ni devenga opresivo para quien lo recibe.

Empero, el demócrata, nos parece, permanecería por así decir despersonalizado si las acciones en las que desgrana su conducta respondieran a propiedades prendidas en su espíritu de manera independiente, como desconectadas entre sí. Si no mediara entre ellas una conciencia que las actuara y les trazara su orden y lugar. Por eso creemos que la mayor diferencia entre el héroe antiguo, que fiaba al éxito de sus proezas -en la guerra o en los juegos, como Homero o Píndaro poetizaron- su anhelado logro de eternizarse mediante la gloria, ${ }^{21}$ y el actual reside precisamente en el traslado del éxito a la propia acción del criterio moral y de la ulterior canonización como héroe de la persona que la lleva a cabo, vale decir, en la valorización de la acción por sí misma con independencia del resultado obtenido con ella. Y por eso también creemos advertir la presencia de este demiurgo moral al que no se nombra en las palabras que, entendemos, provendrían de él; en efecto, tras haber proclamado que la grandeza de Atenas se alza sobre el pedestal de los hechos y no de su posterior poetización

\footnotetext{
20 "Y quien ha hecho el favor está en mejores condiciones para conservar vivo, mediante muestras de benevolencia hacia aquel a quien concedió el favor, el agradecimiento que se le debe" (Tucídides, 2000, p. 455). No es éste el lugar para criticar semejante ingenuidad, por no decir algo peor, en el razonamiento de Pericles: las sirenas de Odiseo ya nos había enseñado, ocultando el enorme amasijo de calaveras, bajo la dulzura irresistible de sus cantos, los peligros de acciones como ésas: la moral, incluida la más pura, nunca es del todo inocente en sus consecuencias por mucho que lo sea en sus principios, y por lo tanto no es ajena a la esclavitud o a la violencia que puede surgir de los favores con independencia de la ingenuidad de las intenciones: Hobbes ya nos mostró algo sobre eso.

${ }^{21}$ Kléos, la "gloria que se desarrolla de boca en boca, de generación en generación", pero que presupone el Kúdos, "la gloria que ilumina al vencedor... una suerte de gracia divina, instantánea", al decir de M. Détienne (2006, p. 74). Por lo demás, también la mujer gozó de gloria, especialmente en la tragedia - al respecto, cf. Gerolemou (2012).
} 
por un futuro Homero, y con ello la superioridad de Atenas sobre Troya, más tarde igualmente afirmada por Isócrates, ${ }^{22}$ y que aquellos hechos son los que su audacia extrajo de sus incursiones por "todo el mar y por toda la tierra", Pericles concluye: "nos bastará... con haber dejado por todas partes

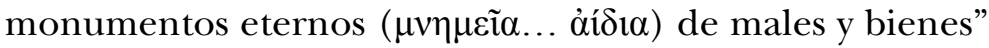
(Tucídides, 2000), ${ }^{23}$ es decir, de sus éxitos y de sus fracasos: de unos $y$ otros por igual.

Un fracaso como manifestación de éxito resultaría inconcebible para el héroe antiguo, quien probablemente se habría quitado la vida antes que presentarse derrotado ante los suyos, o de exponerse a sus posibles burlas o lamentos. Sin embargo, la conciencia del demócrata, del ciudadano ateniense, le autoriza a suprimir el nexo natural entre la acción y sus consecuencias y de vincularla a la intención de la que partió para valorarla moralmente. Una gran empresa es, pues, valor por sí misma aunque se salde en fracaso. $\mathrm{Su}$ grandeza no espera al triunfo, porque el valor, el cálculo, la osadía ya dejaron sus señas de identidad en su concepción, su planificación y su ejecución. El éxito habría sin duda coronado el proyecto de felicidad personal o colectiva; el fracaso, sin embargo, carece de autoridad para arrebatarle el título moral con el que irrumpió en la mente antes de presentarse en sociedad. El resultado ha dejado satisfecha a la conciencia que la autorizó con independencia del fracaso en que se saldó, lo que la consagra como daímon del nuevo mundo moral. Antes de que Sócrates apelara al suyo en justificación de sus actos, o de que Demócrito, confutando las

\footnotetext{
${ }^{22}$ Y con esto la de la historia sobre el mito, así como la de la verdad sobre la representación literaria.

${ }^{23}$ Damos completa la cita en el original del par. 41, 4: $\mu \varepsilon \tau \grave{\alpha} \mu \varepsilon \gamma \alpha \dot{\lambda} \lambda \omega v \delta \dot{\varepsilon} \sigma \eta \mu \varepsilon i ́ \omega v$

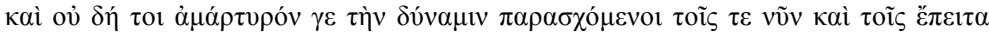

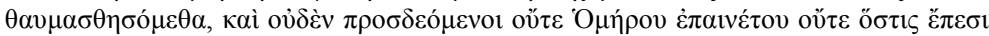

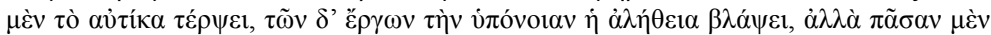

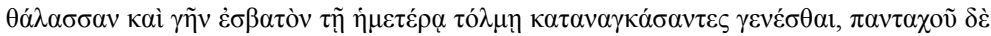

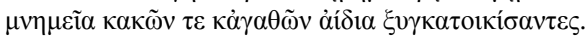


ideas de Antifonte, para quien la justicia debe respetarse sólo en presencia de testigos, afirmara que había que seguir el bien hubiera testigos o no (Antifonte, 1996), el sujeto de la democracia ya había confirmado el viaje de la moral desde el mundo exterior al mundo interior al transformar la conciencia en criterio del bien y del mal, y soltado el lastre del éxito durante el mismo como demostración de su verdad. ${ }^{24}$

\section{Epílogo}

Donde con mayor énfasis se palpa el orgullo del orador es en el resumen de la parte pública de su discurso, cuando considera a Atenas el modelo de Grecia ${ }^{25}$ y al ateniense el modelo de hombre. Quien observe con atención al ciudadano no dejará de advertir la riqueza de sus cualidades, la variedad de sus capacidades, la versatilidad de su conducta, que le cualifican en abstracto para cualquier actividad y le auguran notoriedad en su desempeño. Recordar esa dote de su historia y su cultura, que consiste en una "gracia y una habilidad extraordinarias", como hace el orador, es sólo una forma de hacerle justicia, que se completa añadiendo la armonía de su personalidad merced a la sabia conjunción de cuerpo y espíritu, de sensibilidad y razón. Hablar de ese demócrata por ese motivo es por lo tanto datar en cierto modo el inicio de los deseos convertidos acto seguido en ideales de algunos grandes pensadores del renacimiento, como Castiglione, o de las aspiraciones del romanticismo,

\footnotetext{
${ }^{24}$ Sobre las relaciones internas de Tucídides con la intelectualidad contemporánea, tema no tratado en el presente artículo pero sí aludido en algunas referencias, el lector puede ver el capítulo de Tsakmakis (2016). Cf. también Christodoulou (2017). Imprescindibles aún siguen siendo las magnas obras de F. Rodríguez Adrados (1993) y M. A. Levi (1996). Por lo demás, recuérdese cuánto de la grandeza de Pericles atribuía Plutarco a su trato con Anaxágoras (Vida de Pericles, 5).

${ }^{25}$ En realidad, aquí restringe notablemente la capacidad de su modelo de prender en toda sociedad, que era lo que había sugerido al inicio de su intervención, cuando sabedor de la doble condición de los extranjeros que le escuchaban, grie-

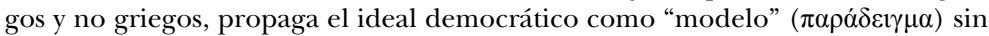
reparar en tales distinciones (Tucídides, 2000).
} 
refrendadas por un Humboldt o por el Goethe del primer Wilhelm Meister, de dar forma mediante la Bildung a un hombre que por la armonía entre su mente y su corazón desplegara una vida similar a una obra de arte.

Ahora bien, con independencia de su posible pedigrí histórico, lo cierto es que el conjunto de atributos que Pericles reúne en el haz del ciudadano ateniense conforma a un sujeto que no sólo representa una novedad humana radical, sino que eleva la configuración de la misma hasta un nivel desconocido. Con su cultura del esfuerzo y del realismo evitan sufrimientos ociosos en los individuos, propagan el placer por la vida, elevan la espiritualidad, practican la auto-confianza y la cooperación, no renuncian a su responsabilidad, sintetizan cualidades dispersas y aun opuestas, armonizan las potencias vitales constitutivas de lo humano, etc. Ello les permite, en suma, regir sus destinos personales tanto como el destino común, y relacionarse con los demás 52 por medio de la generosidad y el valor. En esa renovada especie humana integrada por individuos más complejos y singulares toma forma la antropología de la democracia.

\section{Antonio Hermosa Andújar}

es profesor de Historia de la Ideas Políticas en la Universidad de Sevilla, temática sobre la que versan la inmensa mayoría de sus publicaciones, la última de las cuales data de febrero de 2019 y lleva por título El hombre tras los hechos. Naturaleza humana y política en la historiografía antigua. Ha traducido a clásicos políticos, como Maquiavelo, Guicciardini, Hobbes, Diderot, Rousseau, Tocqueville, Marx y Herzl entre otros. Asimismo, es director de Araucaria. Revista Iberoamericana de Filosofia, Política, Humanidades y Relaciones Internacionales.

\section{Bibliografía}

ANTIFONTE. 1996. Fragmento A, Col. I (1-33 Hunt). In: SOFISTAS.

Testimonios y fragmentos. Madrid: Gredos. pp. 357-359. 
CHRISTODOULOU, Panos. 2017. Thucydides Philosophistoricus: the way of life of the historian. Araucaria. Revista Iberoamericana de Filosofia, Política y Humanidades, v. 19, n. 37, pp. 151-167.

DÉTIENNE, Marcel. 2006. Les Maîtres de Vérité dans la Grèce archaïque. Paris: Librairie Générale Française.

DOMÍNGUEZ MONEDERO, Adolfo J. 2013. El discurso fúnebre: el epitaphios logos de Pericles en Tucídides. In: FORNIS, César (ed.). Los discursos del poder / El poder de los discursos en la Antigüedad clásica. Zaragoza: Libros Pórtico. pp. 19-37.

FINLEY, Moses Isaac. 1962. Athenian Demagogues. Past and Present, n. 21, pp. 3-24.

GEROLEMOU, Von Maria. 2012. Zum Problem des Weiblicher Ruhm in der Griechischen Tragödie. Classica et Mediaevalia, n. 63. pp. 33-71.

GEROLEMOU, Von Maria. 2017. Thinking of Autonomy as Automatism: the case of autonomy in Thucydides history. Araucaria. Revista Iberoamericana de Filosofía, Política y Humanidades, v. 19, n. 37. pp. 199-211.

HERMOSA ANDÚJAR, Antonio. 2000. Pericles y el ideal de la democracia ateniense. Res Publica, n. 5, pp. 45-72.

HERMOSA ANDÚJAR, Antonio. 2008. La "Oración fúnebre" de Pericles: el discurso fundacional de la democracia. La Casa del Tiempo, v. 1, n. 5/6, pp. 77.84 .

LEVI, Mario Attilio. 1996. Pericle e la democrazia ateniese. Milano: Rusconi.

MACHIAVELLI, Niccolò. 2006. La Mandragola [en Opere]. Milano: Biblioteca Treccani.

MEIER, Christian. 1983. Die Entstehung des Politischen bei den Griechen. Frankfurt am Main: Suhrkamp Verlag.

MEIER, Christian. 1993. Athen: Ein Neubeginn der Weltgeschichte. Berlin: Goldmann Verlag.

MUSTI, Domenico. 2000. Demokratía. Orígenes de una idea. Madrid: Alianza Editorial.

PLATÓN. 2000. La República. Madrid: Gredos.

PLUTARCO. 2001. Vida de Pericles. Madrid: Gredos.

RHODES, Peter John. 2004. Athenian Democracy. Oxford: Oxford University Press.

RODRÍGUEZ ADRADOS, Francisco. 1993. La democracia ateniense. Madrid: Alianza Universidad.

SANCHO ROCHER, Laura. 2017. Los agentes de la historia en los excursos sobre el pasado de Tucídides. Araucaria. Revista Iberoamericana de Filosofia, Política y Humanidades, v. 19, n. 37, pp. 235-256. 
TSAKMAKIS, Antonis. 2016. Historiography and Biography. In: HOSE, Martin; SCHENKER, David (org.). A Companion to Greek Literature.

London: Willey Blackwell. pp. 217-234.

TSAKMAKIS, Antonis. 2017. Old and Young in Thucydides: experience, learning, and themistocles. Araucaria. Revista Iberoamericana de Filosofia, Política y Humanidades, v. 19, n. 37, pp. 169-180.

TUCÍDIDES. 2000. Historia de la Guerra del Peloponeso. Madrid: Gredos.

VIDAL-NAQUET, Pierre. 1990. La raison grecque et la cité. In: VERNANT, Jean-Pierre; VIDAL-NAQUET, Pierre. La Grèce ancienne. I. Du mythe à la raison. Paris: Maspero. 


\section{LA ANTROPOLOGÍA DE LA DEMOCRACIA. EL DEMÓCRATA EN LA ORACIÓN FÚNEBRE DE PERICLES}

\section{ANTONIO HERMOSA ANDÚJAR}

Resumen: En el presente artículo nos proponemos reflexionar acerca de por qué en la Oración Fúnebre de Pericles la democracia produce individuos cualitativamente superiores a los demás regímenes políticos y cómo son. Y nuestra conclusión es que, dignos sucesores de la herencia de sus antepasados, no sólo multiplicaron la herencia ampliando el imperio, sino transformando también la autoctonía en autarquía y con ella en libertad. A la convicción del esfuerzo como medio de lograr sus objetivos sumaron el valor de la responsabilidad (tanto en su vida pública como en su vida privada, uniendo así la autonomía y la tolerancia personales a la libertad, la igualdad y el mérito públicos) y el del hedonismo, que lograron compatibilizar con el valor y la planificación racional de sus empresas. Finalmente, consideró dignos de recuerdo no sólo los éxitos, sino también los fracasos, esto es, trasladó la moralidad desde el mundo exterior al mundo interior, regido ya por la conciencia.

Palabras clave: Pericles; Atenas; Democracia; Individualismo; Libertad; Igualdad; Mérito; Valores; Acción; Conciencia.

\section{A ANTROPOLOGIA DA DEMOCRACIA. O DEMOCRATA NA ORAÇÃO FÚNEBRE DE PÉRICLES}

Resumo: No presente artigo nos propomos refletir acerca do porquê, na Oração Fúnebre de Péricles, a democracia produz indivíduos qualitativamente superiores aos demais regimes políticos. A conclusão é que, como dignos sucessores da herança de seus antepassados, não somente multiplicaram a herança ampliando o império, senão transformando, também, a autoctonia em autarquia e esta em liberdade. À convicção do esforço como meio de alcançar seus objetivos 
somaram-se o valor da reponsabilidade (tanto em sua vida pública quanto privada, unindo assim a autonomia e a tolerância pessoais à liberdade, à igualdade e ao mérito públicos) e o hedonismo, que buscaram compatibilizar com o valor e a planificação racional de seus empreendimentos. Dai surgiu um indivíduo novo, que sintetizava em sua pessoa ao menos dois dos não democratas e liberava o raio de ação dos valores para reger relações sociais até então desconhecidas. Finalmente, considerou dignos de recordação não somente os êxitos, senão também os fracassos, isto é transladou a moralidade desde o mundo exterior ao mundo interior, regido pela consciência.

Palavras-chave: Péricles; Atenas; Democracia; Individualismo; Liberdade; Igualdade; Mérito; Valores; Ação; Consciência.

\section{THE ANTHROPOLOGY OF DEMOCRACY. THE DEMOCRAT IN THE FUNERAL ORATION OF PERICLES}

Abstract: The article examines the reason why, according to Pericles' Funeral Oration, democracy produces individuals qualitatively superior to those in other political regimes and what they are like. And our conclusion is that, as worthy successors of the inheritance of their ancestors, they not only multiplied their inheritance by extending the empire, but also by transforming the autochthony into autarchy and, by it, into freedom. To the conviction that effort was the means to achieve their goals they added the value of responsibility (both in their public life and in their private life, thus uniting personal autonomy and tolerance to public liberty, equality and merit) and the value of hedonism, which they managed to combine with the bravery and rational planning of their ventures. Finally, he regarded as worthy of memory not only successes but also failures, that is, he transferred morality from the outside world to the inner world, which was already ruled by conscience.

Keywords: Pericles; Athens; Democracy; Individualism; Freedom; Equality; Merit; Values; Action; Conscience.

Recebido: 27/09/2018 Aprovado: 16/07/2019 